\title{
Histopathological Classification of Lesions Observed in Natural Cases of Paratuberculosis in Free-ranging Fallow Deer (Dama dama)
}

\author{
A. Balseiro* , J. F. García Marín ${ }^{\dagger}$, P. Solano*, \\ J. M. Garrido ${ }^{\ddagger}$ and J. M. Prieto* \\ *SERIDA, Servicio Regional de Investigación y Desarrollo Agroalimentario, Laboratorio de Sanidad Animal, 33299 Jove, \\ Gijón, Asturias, ${ }^{\dagger}$ Departamento de Patología Animal, Medicina Animal (Anatomia Patológica), Facultad de Veterinaria, \\ Universidad de León, Campus de Vegazana s/n, 24071 León, and ${ }^{\ddagger} \mathcal{N E I K E R , ~ I n s t i t u t o ~ V a s c o ~ d e ~ I n v e s t i g a c i o ́ n ~ y ~ D e s a r r o l l o ~}$ \\ Agrario, 48160 Derio, Vizcaya, Spain
}

\begin{abstract}
Summary
Ninety-five adult fallow deer, legally hunted in the Regional Hunting Reserve of El Sueve (Northern Spain), were subjected to a post-mortem examination for paratuberculosis, samples being taken from the proximal and distal jejunum, proximal and distal ileum, ileocaecal valve and associated lymph nodes. The lesions were divided into four categories. Focal lesions $(n=19$ cases) consisted of small granulomas, mainly in the jejunal and ileal lymph nodes. Multifocal lesions $(n=4)$ consisted of well-demarcated granulomas in the intestinal lymphoid tissue and also in the intestinal lamina propria. Diffuse multibacillary lesions $(n=2)$ were characterized by a severe granulomatous enteritis and lymphadenitis. Macrophages and numerous Langhans giant cells containing many mycobacteria were present, resulting in macroscopical changes in the normal gut morphology. These changes were found from the proximal jejunum to the ileocaecal valve, but lesions were always particularly severe in the distal jejunum. In diffuse intermediate (multibacillary-lymphocytic) lesions $(n=3)$ the infiltrate consisted of lymphocytes, macrophages and Langhans giant cells, with small numbers of mycobacteria. Mycobacterium avium subspecies paratuberculosis was identified by a polymerase chain reaction technique. The widespread occurrence of paratuberculosis in fallow deer in this Reserve represents a potential source of infection for other susceptible species.
\end{abstract}

(C) 2008 Elsevier Ltd. All rights reserved.

Keywords: bacterial infection; Dama dama; fallow deer; Johne's disease; Mycobacterium avium subsp. paratuberculosis; paratuberculosis lesions

\section{Introduction}

Paratuberculosis (Johne's disease) is a chronic ruminant infectious disease caused by Mycobacterium avium subspecies paratuberculosis (Map). Infection is usually initiated soon after birth, but clinical signs may take years to develop (Clarke, 1997). Clinical disease is characterized by a progressive, afebrile weight loss that leads to emaciation and diarrhoea (Chiodini et al., 1984). Paratuberculosis is well studied in domestic ruminants, but there are relatively few reports in free-ranging deer (Jessup and Williams, 1999; Pavlik et al., 2000; Álvarez et al., 2005), infection in such

Correspondence to: A. Balseiro (e-mail: abalseiro@serida.org). animals having been first diagnosed in five free-ranging fallow deer (Dama dama) in Spain in 1997 (Marco et al., 2002). Classification of lesions has been described in sheep (Stamp and Watt, 1954; Carrigan and Seaman, 1990; Pérez et al., 1996), goats (Paliwal et al., 1985; Corpa et al., 2000) and cattle (Buergelt et al., 1978; González et al., 2005). In ovine paratuberculosis, Pérez et al. (1996) described small "tuberculoid" granulomas in the ileocaecal lymphoid tissue (Peyer's patches). This type of lesion, also referred as a "focal lesion", was later reported in goats (Corpa et al., 2000) and cattle (González et al., 2005). A "multibacillary" form, in which macrophages were filled with numerous mycobacteria, was also described (Carrigan and Seaman, 1990; Pérez et al., 1996; 
Clarke, 1997; Corpa et al., 2000; González et al., 2005). The immune response plays an important role in determining the histopathological type of paratuberculosis. Whereas "tuberculoid" types are associated with a strong peripheral cellular immune response, "multibacillary" types are associated with a marked humoral immune response (Clarke et al., 1996; Pérez et al., 1997, 1999; Corpa et al., 2000; González et al., 2005).

The aims of the present study were (1) to determine the prevalence of paratuberculosis in free-ranging fallow deer in the Regional Hunting Reserve of El Sueve Asturias (Northern Spain), and (2) to classify histopathologically the paratuberculosis-associated lesions in the intestinal lymphoid tissue and lymph nodes.

\section{Materials and Methods}

Animals

This study was based on 95 adult fallow deer (58 females and 37 males) legally hunted in the Regional Hunting Reserve of El Sueve (Principado de Asturias, in Northern Spain; $\left.43^{\circ} 15^{\prime} \mathrm{N}, 5^{\circ} 15^{\prime} \mathrm{W}\right)$ during the 2004-2007 period.

\section{Pathological Examination}

Gross lesions observed in hunted animals were recorded, attention being focused on the gut and associated lymph nodes. Samples for histopathology were taken from the proximal and distal jejunum, proximal and distal ileum, ileocaecal valve, and associated lymph nodes. They were fixed in $10 \%$ neutral buffered formalin and dehydrated through graded alcohols and xylol before being embedded in paraffin wax. Several sections $(4 \mu \mathrm{m})$ were cut from each sample and stained with haematoxylin and eosin (HE) and by Ziehl-Neelsen's (ZN) method for acid-fast bacteria (AFB). In selected positive cases showing paratuberculosis lesions, immunohistochemical examination by means of the peroxidase anti-peroxidase (PAP) method was performed. The sections were incubated with specific antiserum (rabbit), diluted 1 in 1000 , prepared by hyperimmunizing two rabbits with a "sonicated" extract of a Map strain (A-82) isolated from the intestinal tissues of a cow (Balseiro et al., 2003). To evaluate the specificity of the anti-Map antibody, tissue samples from a paratuberculous cow were used. Pre-immunization rabbit serum was used as a negative control.

\section{Polymerase Chain Reaction (PCR)}

The PCR technique as described by Challans et al. (1994) was used to examine fresh tissue samples from the jejunum, ileum, ileocaecal valve and associated lymph nodes. RJ1-PT91 primers (Garrido et al., 2000) were selected to amplify a $388 \mathrm{bp}$ fragment of the IS900 insertion sequence specific for Map. The fragments were detected by agarose gel electrophoresis.

\section{Results}

\section{Gross Lesions}

Macroscopical changes were observed only in the intestines and lymph nodes of animals with diffuse lesions (see below), intestinal wall thickening and lymph node enlargement being observed. Lymphangiectasis was not recorded.

\section{Histopathological, Immunohistochemical and PCR Findings}

Stained sections were examined for typical paratuberculous lesions and AFB. The lesions (granulomas) were classified on the basis of (1) their location, intensity and inflammatory cell type, and (2) their numerical content of mycobacteria. An animal was considered positive, as judged histopathologically, if any sample showed one of the four categories of lesion listed below. On this basis, $28(29.47 \%)$ of the 95 fallow deer examined were positive.

Focal lesions. This type of lesion, seen in $19(20 \%)$ fallow deer, was characterized by well-demarcated, small granulomas formed by macrophages, small numbers of lymphocytes, and multinucleated Langhans giant cells. The latter were either isolated or in groups (Fig. 1). These granulomatous lesions occurred sporadically in the interfollicular areas of the intestinal lymphoid tissue. They occurred more commonly, however, in the cortex and paracortex of the mesenteric and ileocaecal lymph nodes, and particularly in the distal jejunal and proximal ileal lymph nodes. Granulomas were always focal and never sufficiently numerous to cause diffuse enteritis or to modify the normal architecture of the intestine or lymph nodes. AFB were not demonstrated by $\mathrm{ZN}$ stain, but macrophages and giant cells forming the granulomas were immunolabelled by the anti-Map antibody. The PCR method gave positive results in four fallow deer with this type of lesion.

Multifocal lesions. Lesions of this type, which were present in four $(4.21 \%)$ animals, consisted of welldemarcated granulomas in the intestinal lymphoid tissue and also in the intestinal lamina propia. Granulomas were located in some of the villi, usually in the apex, causing focal thickening of the mucosa (Fig. 2). They were not sufficiently numerous, however, to cause diffuse enteritis or to modify significantly the normal architecture of the intestine. Normal villi 


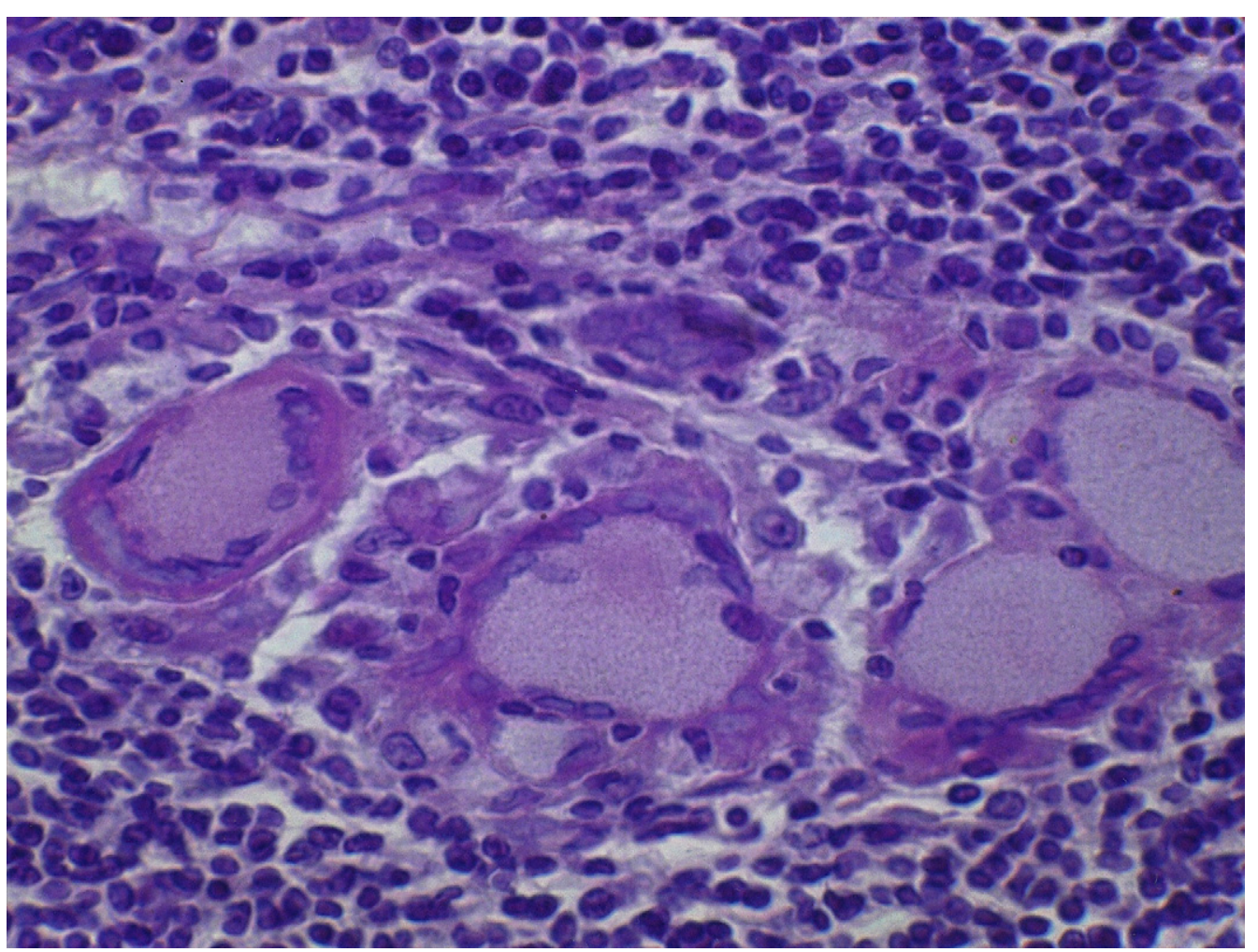

Fig. 1. Focal lesion. Small granuloma formed by macrophages and Langhans giant cells, located in the interfollicular area of the distal jejunal lymph node. HE. $\times 400$.

were present adjacent to affected villi. Small numbers of granulomas were located in the interfollicular areas of the lymph nodes. In one animal, a few entire mycobacteria were demonstrated by $\mathrm{ZN}$ stain. Immunolabelling was detected in macrophages and giant cells within the granulomas. The PCR gave positive results in two animals with this type of lesion.

Diffuse lesions. Lesions of this type, which occurred in animals with severe granulomatous enteritis and lymphadenitis, were divided into two different subtypes, according to the nature of the cells present in the infiltrate and the amount of AFB.

Diffuse multibacillary lesions. In the two $(2.1 \%)$ animals with this type of lesion, the intestinal wall was thickened and the lymph nodes were enlarged. An infiltrate consisting of epithelioid cells, lymphocytes, macrophages and numerous Langhans giant cells was observed. In the lamina propia, the villi were commonly fused due to this infiltrate (Fig. 3), which had a mosaic-like appearance. In some sections, granulomas were seen in the villi (Fig. 3). The intestinal glands were occasionally dilated and filled with necrotic debris. The submucosa was affected in both animals, showing an infiltrate consisting mainly of macrophages and plasma cells. The Peyer's patches showed either a severe granulomatous infiltrate that invaded the lymphoid follicles, or multifocal granulomas located in the interfollicular zone. The serosa was less affected. Multifocal granulomatous infiltrates were associated with lymph vessels, giving rise to inflammation and thrombus formation. Such changes were observed, from the proximal jejunum to the ileocaecal valve, in only one animal and were particularly severe in the distal ileum. Lymph nodes (especially the distal jejunal) showed a severe and diffuse granulomatous lymphadenitis, with macrophages and abundant giant cells, which caused a significant alteration of the normal lymph node architecture (Fig. 4). Mycobacteria in large numbers were invariably demonstrated, by the ZN technique, in all sections of intestine and lymph nodes (Fig. 5). Intensive positive immunolabelling was observed in the intestine and lymph nodes (Fig. 6). The PCR gave positive results in both deer with this type of lesion.

Diffuse intermediate (multibacillary-lymphocytic) Lesions. The three $(3.16 \%)$ animals with this type of lesion had diffuse granulomatous enteritis. The intestinal villi and lamina propia were infiltrated with inflammatory cells, causing shortening and thickening of the villi (Fig. 7). The infiltrate contained a large number of macrophages and lymphocytes. Giant cells were present but always fewer than in the diffuse multibacillary lesions. The 


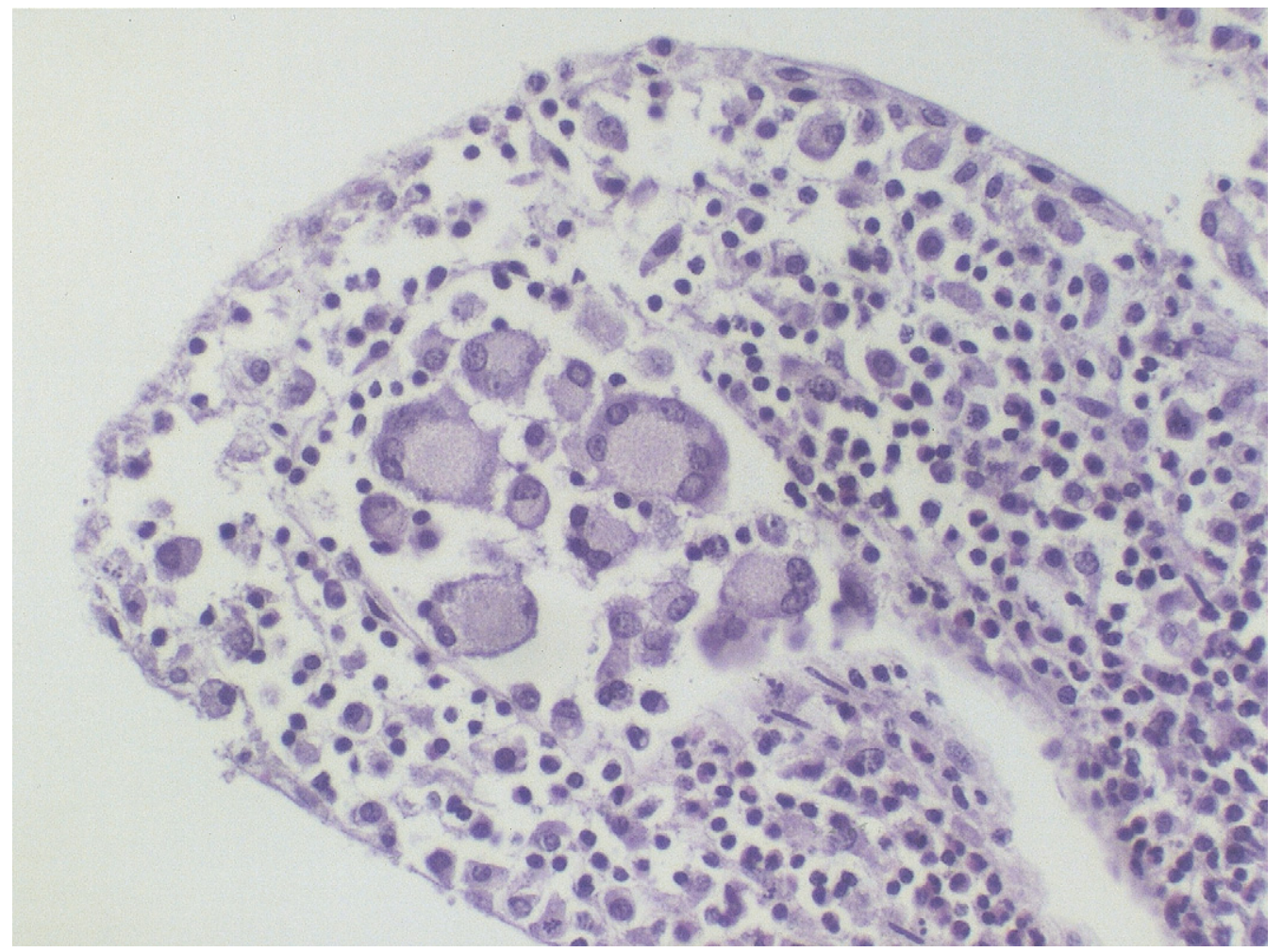

Fig. 2. Multifocal lesion. Distal jejunum. Granuloma located in the apex of the intestinal villus, causing focal thickening of the mucosa. HE. $\times 200$.

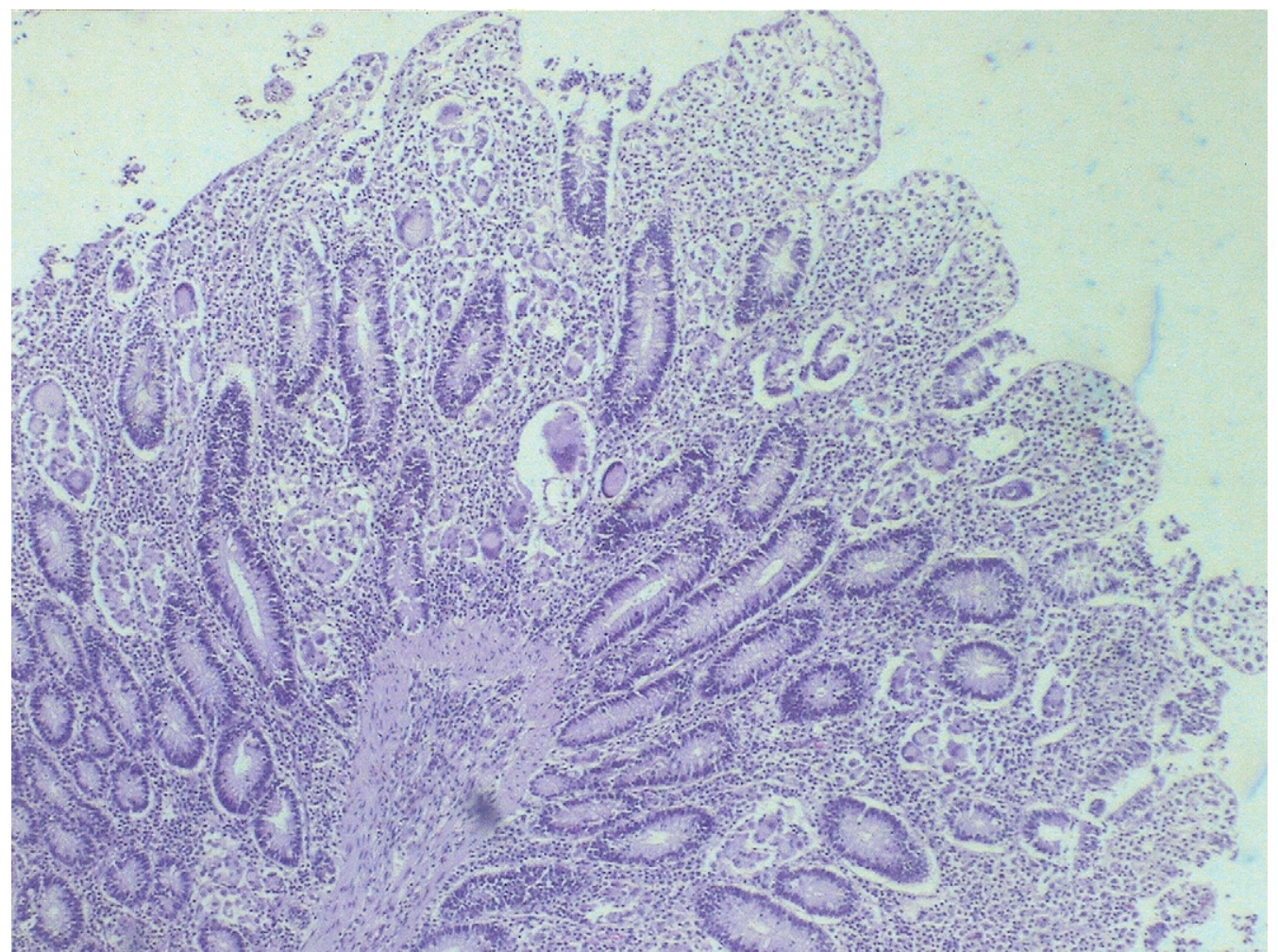

Fig. 3. Diffuse multibacillary lesion. Distal jejunum. Inflammatory infiltrate formed mainly by macrophages, causing thickening of the mucosa. Villi fused due to this infiltrate. HE. $\times 40$. 


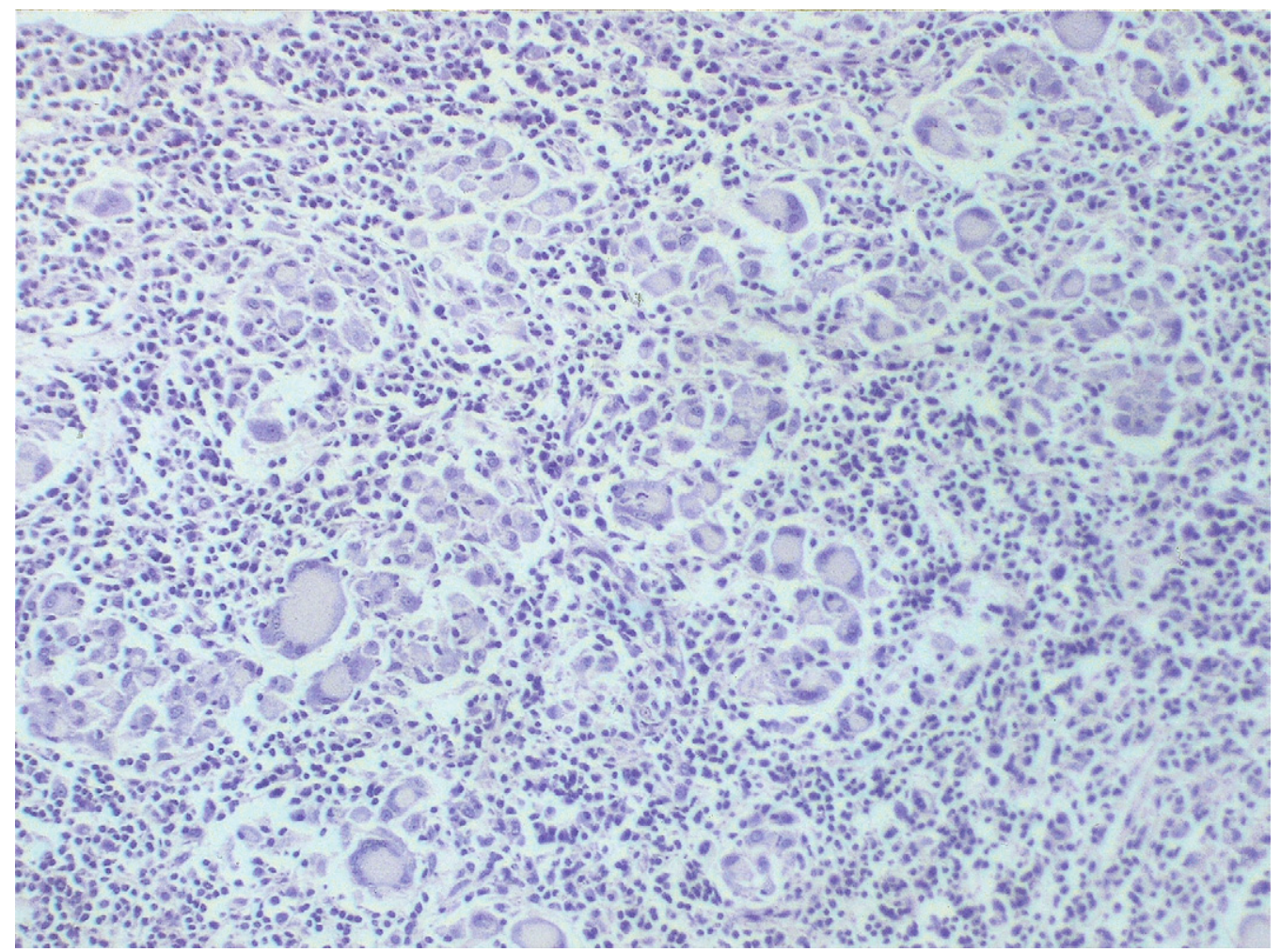

Fig. 4. Diffuse multibacillary lesion. Distal jejunal lymph node. Severe and diffuse granulomatous lymphadenitis with macrophages and abundant Langhans giant cells, which cause a significant alteration of the normal lymph node architecture. HE. $\times 100$.

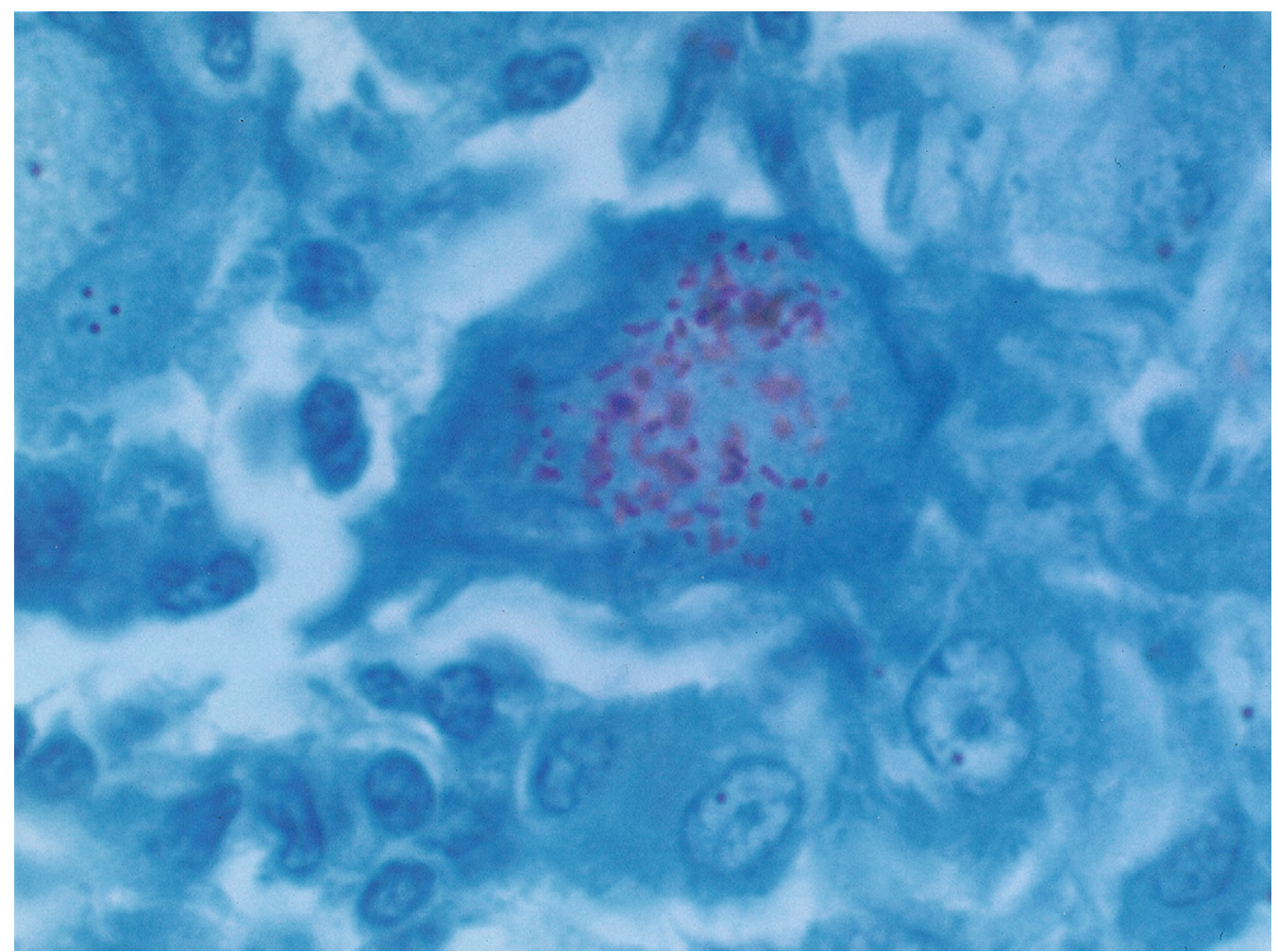

Fig. 5. Diffuse multibacillary lesion. Distal jejunal lymph node. Langhans giant cell filled with large number of mycobacteria. ZN. $\times 1000$. 


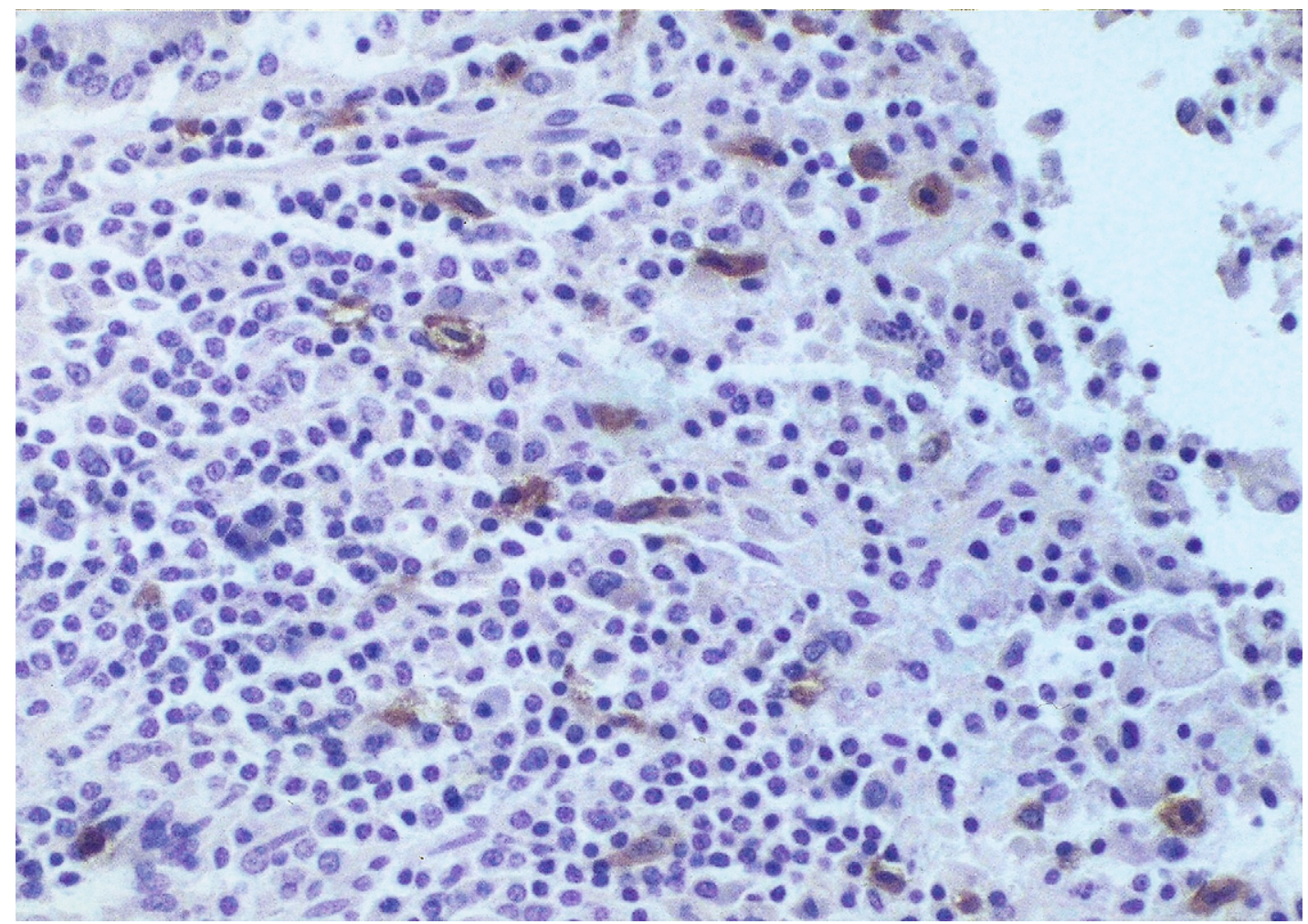

Fig. 6. Diffuse multibacillary lesion. Distal jejunum. Positive immunolabelling in macrophages. PAP. $\times 200$.

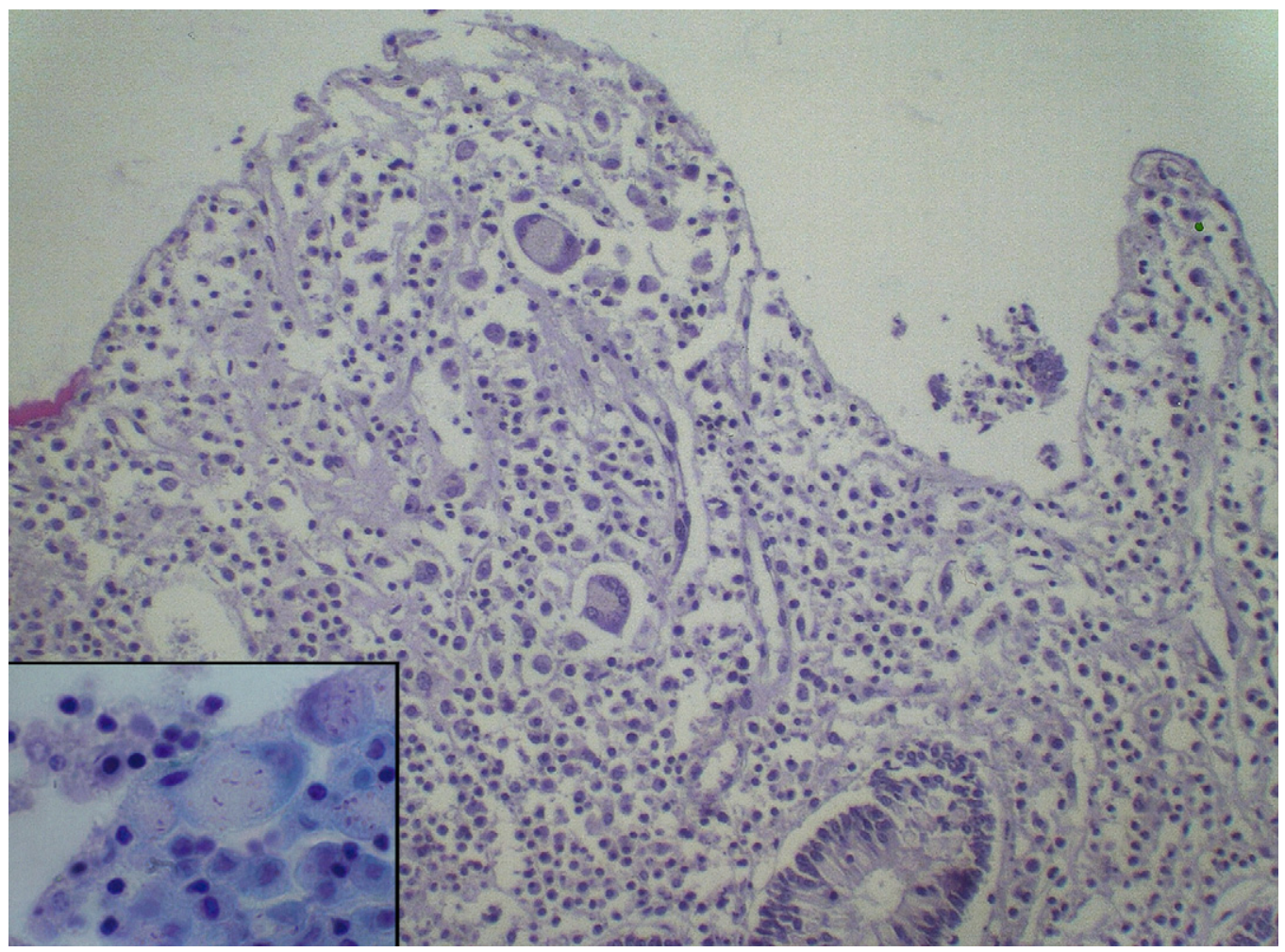

Fig. 7. Diffuse intermediate lesion. Ileocaecal valve. Intestinal villi infiltrated with inflammatory cells, causing shortening and thickening of the villi. The infiltrate contains macrophages, lymphocytes and occasional Langhans giant cells. HE. $\times 100$. Inset: Langhans giant cells contain small numbers of mycobacteria. ZN. $\times 400$. 
submucosa showed an inflammatory infiltrate consisting of plasma cells, macrophages and lymphocytes. The serosa was not affected. No differences were found between different areas of the intestine. In the lymph nodes, a granulomatous lymphadenitis was observed, mainly in the distal jejunal and proximal ileal samples (Fig. 8). Langhans giant cells were observed, mainly in the cortex. AFB were demonstrated by $\mathrm{ZN}$ staining but in smaller numbers than in lesions of the diffuse multibacillary type (Fig. 7). Mycobacteria were also demonstrated immunohistochemically. The PCR gave positive results in two of the three deer with this type of lesion.

\section{Discussion}

The percentage of free fallow deer from the El Sueve Regional Hunting Reserve with paratuberculosis lesions was high $(29.47 \%)$. This Reserve (8300 ha) is a mountainous area of Asturias. Fallow deer were introduced in 1960, and in 2006 the population was estimated to be approximately 500 (data from Consejería de Medio Ambiente). Cattle, horses, sheep and goats share pastures and waterholes with the deer. In Spain and in Asturias, the prevalence of bovine paratuberculosis was estimated to be $31.3 \%$ (Juste et al., 2000) and 44.39\% (Balseiro, 2004), respectively. Thus, the prevalence of paratuberculosis in fallow deer in the Reserve seemed a matter of potential epidemiological significance.

The classification parameters of paratuberculosis lesions proposed for other species appeared to be valid for fallow deer. Thus, this study confirmed that the histological lesions in this species resembled those observed in small ruminants and cattle (Pérez et al., 1996; Corpa et al., 2000; González et al., 2005). The focal lesions described were reported previously in the early stages of Map infection (Juste et al., 1994; Sigurdardóttir et al., 1999; Kurade et al., 2004). It was suggested (Pérez et al., 1996; González et al., 2005) that in sheep and cattle the focal form represented lesions that developed early in life and were limited by the immune response, but nonetheless persisted. The focal lesions were the form most commonly found in fallow deer in the present study. This may indicate that this species has the ability to control the progression of the infection. The animals examined were all adults and as such may have possessed some resistance to infection (Larsen et al., 1975; Clarke, 1997). As in cattle (González et al., 2005), focal lesions in fallow deer were mainly encountered in lymph nodes. In sheep and goats, however, such lesions are frequently found in the intestinal lymphoid tissue (Pérez et al., 1996; Corpa et al., 2000). Multifocal lesions, which occur mainly in subclinically infected animals, may

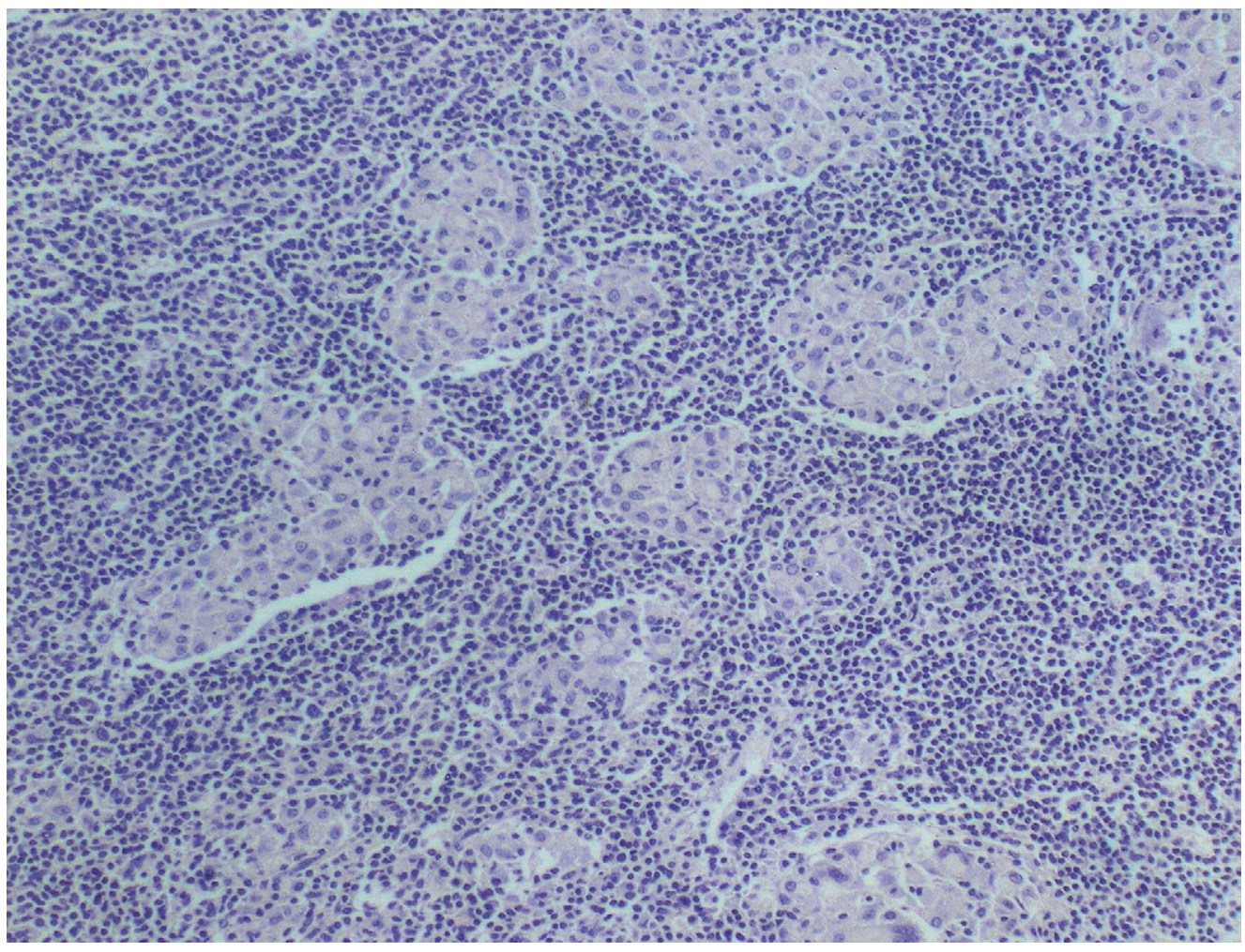

Fig. 8. Diffuse intermediate lesion. Distal jejunal lymph node. Severe granulomatous lymphadenitis. HE. $\times 100$. 
represent progression of the infection after failure of the immune response. The diffuse multibacillary form has been widely reported by different authors (Buergelt et al., 1978; Huda and Jensen, 2003). In the present study this type of lesion was associated with a severe thickening of the intestinal wall, as described previously in cattle and sheep (Pérez et al., 1996; González et al., 2005). However, this association seems to be uncommon in goats (Paliwal et al., 1985; Vialard et al., 1990; Corpa et al., 2000). Lymphangiectasis and granulomatous infiltrates associated with lymph vessels were observed in only one animal. Such changes are common in sheep and cattle (Pérez et al., 1996; González et al., 2005). Lesions classified as intermediate were previously described in goats (Corpa et al., 2000) and cattle (González et al., 2005); such lesions contained few mycobacteria, possibly due to the presence of macrophages. Diffuse lymphocytic lesions, previously described in cattle, goats and sheep, were not observed in the present study, probably because of the limited number of animals examined.

Multinucleated Langhans giant cells, in numbers even larger than those found in infected cattle, were present in all types of lesion, making this a characteristic feature of fallow deer paratuberculosis; in contrast, in infected sheep and goats such cells are uncommon (Pérez et al., 1996; Clarke, 1997; Corpa et al., 2000). Langhans giant cell formation may be influenced by host factors and by the infecting strain of Map (González et al., 2005). Necrosis was not observed but has been reported frequently in goats (Vialard et al., 1990; Menchén, 1995; Corpa et al., 2000) and occasionally in sheep (Stamp and Watt, 1954).

The jejunum, ileum and associated lymph nodes would seem to be the site of choice for seeking evidence of paratuberculosis in fallow deer. Immunohistochemistry is proposed as a complement to histopathology (Navarro et al., 1991; González et al., 2005). A positive immunohistochemical reaction, together with granulomas of typical structure and location, are considered to be reliable indicators of Map infection.

The PCR method has been proposed for the diagnosis of paratuberculosis. The specificity of the insertion sequence IS900 has been demonstrated by different investigators (Kunze et al., 1992; Challans et al., 1994; Pérez et al., 1994; Miller et al., 1999; Coetsier et al., 2000; Garrido et al., 2000; Collins et al., 2002) and may provide the basis for an alternative to culture. The technique failed, however, to detect a significant proportion of animals with focal lesions; this may have been due to inability to detect small numbers of mycobacteria or to the presence of unusual forms of mycobacteria (Pérez et al., 1994).
Finally, it should be borne in mind that the widespread presence of paratuberculosis in fallow deer in the Regional Hunting Reserve represents a potential risk to other susceptible species.

\section{Acknowledgments}

Financial support was provided by project no. RT2005-00082 of the INIA (Spain).

The authors thank the rangers of the National Hunting Reserve of El Sueve (Ramón González de Lena, Marcos Solís, Raúl Fernández, Jorge Méndez and Carlos González) for helping with collection of the animals, and Dr. Kevin Dalton for checking the manuscript.

\section{References}

Álvarez, J., De Juan, L., Briones, V., Romero, B., Aranaz, A., Fernández-Garayzábal, J. F. and Mateos, A. (2005). Mycobacterium avium subspecies paratuberculosis in fallow deer and wild boar in Spain. Veterinary Record, 156, 212-213.

Balseiro, A. (2004). Paratuberculosis bovina: valoración de las reacciones cruzadas con la prueba de la tuberculina, evaluación de técnicas diagnósticas y prevalencia en Asturias. Tesis Doctoral. Universidad de León, Spain.

Balseiro, A., Prieto, J. M., Espí, A., Pérez, V. and García Marín, J. F. (2003). Presence of focal and multifocal paratuberculosis lesions in mesenteric lymph nodes and the ileocaecal valve of cattle positive to the tuberculin test. Veterinary fournal, 16, 210-212.

Buergelt, C. D., Hall, C., McEntee, K. and Duncan, J. R. (1978). Pathological evaluation of paratuberculosis in naturally infected cattle. Veterinary Pathology, 15, 196-207.

Carrigan, M. J. and Seaman, J. T. (1990). The pathology of Johne's disease in sheep. Australian Veterinary fournal, 67, 47-50.

Challans, J. A., Stevenson, K., Reid, H. W. and Sharp, J. M. (1994). A rapid method for the extraction and detection of Mycobacterium avium subspecies paratuberculosis from clinical specimens. Veterinary Record, $\mathbf{1 3 4}$ 95-96.

Chiodini, R. J., Van Kruiningen, H. J. and Merkal, R. S. (1984). Ruminant paratuberculosis (Johne's disease): the current status and future prospects. Cornell Veterinarian, 74, 218-262.

Clarke, C. J. (1997). The pathology and pathogenesis of paratuberculosis in ruminants and other species. Fournal of Comparative Pathology, 116, 217-261.

Clarke, C. J., Patterson, I. A., Armstrong, K. E. and Low, J. C. (1996). Comparison of the absorbed ELISA and agar gel immunodiffusion test with clinicopathological findings in ovine clinical paratuberculosis. Veterinary Record, 139, 618-621.

Coetsier, C., Vannuffel, P., Blondeel, N., Denef, J. F., Cocito, C. and Gala, J. L. (2000). Duplex PCR for differential identification of Mycobacterium bovis, M. avium, and $M$. avium subsp. paratuberculosis in formalin-fixed 
paraffin-embedded tissues from cattle. Fournal of Clinical Microbiology, 38, 3048-3054.

Collins, D. M., De Zoete, M. and Cavaignac, S. M. (2002). Mycobacterium avium subsp. paratuberculosis from cattle and sheep can be distinguished by a PCR test based on a novel DNA sequence difference. Fournal of Clinical Microbiology, 40, 4760-4762.

Corpa, J. M., Garrido, J., García Marín, J. F. and Pérez, V. (2000). Classification of lesions observed in natural cases of paratuberculosis in goats. Fournal of Comparative Pathology, 122, 255-265.

Garrido, J. M., Cortabarria, N., Oguiza, J. A., Adúriz, G. and Juste, R. A. (2000). Use of a PCR method on fecal samples for diagnosis of sheep paratuberculosis. Veterinary Microbiology, 77, 379-386.

González, J., Geijo, M. V., García-Pariente, A., Verna, A., Corpa, J. M., Reyes, L. E., Ferreras, M. C., Juste, R. A., García Marín, J. F. and Pérez, V. (2005). Histopathological classification of lesions associated with natural paratuberculosis infection in cattle. Journal of Comparative Pathology, 133, 184-196.

Huda, A. and Jensen, H. E. (2003). Comparison of histopathology, cultivation of tissues and rectal contents, and interferon-gamma and serum antibody responses for the diagnosis of bovine paratuberculosis. Fournal of Comparative Pathology, 129, 259-267.

Jessup, D. A. and Williams, E. S. (1999). Paratuberculosis in free-ranging wildlife in North America. In: Zoo and Wild Animal Medicine, M. E. Fowler and R. E. Miller, Eds, W.B. Saunders, Philadelphia, pp. 616-620.

Juste, R. A., García Marín, J. F., Peris, B., Sáez de Ocáriz, C. and Badiola, J. J. (1994). Experimental infection of vaccinated and non-vaccinated lambs with Mycobacterium paratuberculosis. Fournal of Comparative Pathology, 110, 185-194.

Juste, R. A., Garrido, J. M., Adúriz, G., Moreno, B., Geijo, M. V., García-Goti, M. and Oguiza, J. A. (2000). Prevalencia de la paratuberculosis bovina en España. In: Proceedings of sixth International Congress of Bovine Medicine, Santiago de Compostela, Spain. pp. 282-285.

Kunze, Z. M., Portaels, F. and McFadden, J. J. (1992). Biologically distinct subtypes of Mycobacterium avium differ in possession of insertion sequence IS901. Journal of Clinical Microbiology, 30, 2366-2372.

Kurade, N. P., Tripathi, B. N., Rajukumar, K. and Parihar, N. S. (2004). Sequential development of histologic lesions and their relationship with bacterial isolation, fecal shedding, and immune responses during progressive stages of experimental infection of lambs with Mycobacterium avium subsp. paratuberculosis. Veterinary Pathology, 41, 378-387.

Larsen, A. B., Merkal, R. S. and Cutlip, R. C. (1975). Age of cattle as related to resistance to infection with Mycobacterium paratuberculosis. American fournal of Veterinary Research, 36, 255-257.

Marco, I., Ruiz, M., Juste, R., Garrido, J. M. and Lavín, S. (2002). Paratuberculosis in free-ranging fallow deer in Spain. Journal of Wildlife Diseases, 38, 629-632.
Menchén, V. (1995). Estudio inmunocitoquímico de la tuberculosis y paratuberculosis caprinas. Tesis Doctoral, Universidad de Murcia, Spain.

Miller, J. M., Jenny, A. L. and Ellingson, J. L. (1999). Polymerase chain reaction identification of Mycobacterium avium in formalin-fixed, paraffin-embedded animal tissues. Fournal of Veterinary Diagnostic Investigation, 11, 436-440.

Navarro, J. A., Bernabé, A., Gómez, M. A., Sánchez, J. and Gómez, S. (1991). Mycobacterial antigen detection by immunohistochemistry in goat paratuberculosis. Zentralblatt für Veterinärmedizin B, 38, 231-237.

Paliwal, O. P., Kumar, P. and Somvanshi, R. (1985). The immune spectrum of Mycobacterium johnei infection in goats. Indian Veterinary fournal, 62, 743-747.

Pavlik, I., Bartl, J., Dvorska, L., Svastova, P., Du Maine, R., Machackova, M., Yayo Ayele, W. and Horvathova, A. (2000). Epidemiology of paratuberculosis in wild ruminants studied by restriction fragment length polymorphism in the Czech Republic during the period 1995-1998. Veterinary Microbiology, 77, 231-251.

Pérez, V., Bolea, R., Chávez, G., Cortabarria, N., Juste, R. A., Badiola, J. J. and García Marín, J. F. (1994). Efficiency of PCR and culture in the detection of Mycobacterium avium subsp. silvaticum and Mycobacterium avium subsp. paratuberculosis in tissue samples of sheep. In: Proceedings of Fourth International Colloquium of Paratuberculosis, Cambridge, United Kingdom. pp. 97-101.

Pérez, V., García Marín, J. F. and Badiola, J. J. (1996). Description and classification of different types of lesion associated with natural paratuberculosis infection in sheep. Fournal of Comparative Pathology, 114, 107-122.

Pérez, V., Tellechea, J., Badiola, J. J., Gutiérrez, M. and García Marín, J. F. (1997). Relation between serologic response and pathologic findings in sheep with naturally acquired paratuberculosis. American Fournal of Veterinary Research, 58, 799-803.

Pérez, V., Tellechea, J., Corpa, J. M., Gutiérrez, M. and García Marín, J. F. (1999). Relation between pathologic findings and cellular immune responses in sheep with naturally acquired paratuberculosis. American Journal of Veterinary Research, 60, 123-127.

Sigurdardóttir, Ó. G., Press, C. M., Saxegaard, F. and Evensen, O. (1999). Bacterial isolation, immunological response, and histopathological lesions during the early subclinical phase of experimental infection of goat kids with Mycobacterium avium subsp. paratuberculosis. Veterinary Record, 36, 542-550.

Stamp, J. T. and Watt, J. A. (1954). Johne's disease in sheep. Fournal of Comparative Pathology, 64, 26-40.

Vialard, J., Garbe, T., Lathigra, R. and Abou-Zeid, C. (1990). Protein antigens: structure, function and regulation. In: Molecular Biology of the Mycobacteria, J. McFadden, Ed., Surrey University Press, London, pp. 1-35.

$\left[\begin{array}{l}\text { Received, fuly 24th, } 2007 \\ \text { Accepted, fanuary 14th, } 2008\end{array}\right]$ 